\title{
Uso da cola n-butil cianoacrilato na sulcoplastia de recessão em coelhos - avaliação histológica
}

\author{
Use of n-butyl cyanoacrylate glue in the recession sulcoplasty in rabbits - \\ histologic study
}

\author{
Fernanda Carpi dos Santos ${ }^{1}$ Sheila Canevese Rahal ${ }^{2}$ Júlio Lopes Sequeira ${ }^{3}$ \\ Sandra Regina Torelli ${ }^{4}$ Irani Quagio Grassioto ${ }^{5}$
}

\section{RESUMO}

O trabalho teve por objetivos analisar a cola composta por n-butil cianoacrilato, como um auxiliar na fixação da cunha óssea no procedimento da sulcoplastia de recessão e sua interferência no processo cicatricial. Foram utilizados nove coelhos da raça Norfolk, machos, com peso inicial entre 3,0 e 3,5 kg. Após anestesia epidural, realizou-se acesso parapatelar medial e seccionou-se uma cunha ósseocartilaginosa em formato de $V$ no sulco da tróclea. No joelho direito, antes da colocação da cunha em seu leito, foram aplicadas duas gotas da cola, ao passo que, no joelho esquerdo, considerado controle, a cunha foi apenas recolocada. Para realização da técnica de exame anatomopatológico, foram submetidos à eutanásia três animais aos cinco, 15 e 30 dias de pós-operatório. Na avaliação macroscópica, notou-se, em ambos os joelhos, a estabilização da cunha ósseo-cartilaginosa em seu leito receptor nos diferentes momentos de observação. Pelo exame histológico foi possível concluir que a cola não induziu o aparecimento de processo inflamatório acentuado e reação do tipo corpo estranho, mas interferiu negativamente, retardando o processo cicatricial.

Palavras-chave: cola, $n$-butil cianoacrilato, sulcoplastia, coelhos, patela.

\section{ABSTRACT}

The aim of this study was to analyze the glue composed by n-butyl cyanoacrylate, as an auxiliary in the fixation of the bone wedge at the recession sulcoplasty procedure and the interference in the healing. Nine male Norfolk rabbits, initially weighing from 3 to $3.5 \mathrm{~kg}$ were used. After epidural anesthesia, a medial parapatellar approach was used and a V-shaped osteochondral wedge was removed from the trochlea. In the right stifle joint, before the osteochondral wedge replacement two glue drops were used. In the left stifle joint, considered as control, the osteochondral wedge was only replaced. Three animals were submitted to euthanasia at five, 15 and 30 days of postoperative period. Macroscopic evaluation showed that in both stifles the osteochondral wedge was stabilized on the receptor bed during all observation periods. It was possible to conclude, based on microscopic evaluation, that the glue did not induce accentuated inflammatory process and foreign body reaction, but it had a negative influence because the healing process was retarded.

Key words: glue, n-butyl cyanoacrylate, sulcoplasty, rabbits, patella.

\section{INTRODUÇÃO}

Entre os métodos de tratamento da luxação de patela em cães, a técnica de sulcoplastia de recessão tem sido considerada uma das mais adequadas para aprofundar o sulco da tróclea (SLOCUM \& SLOCUM, 1993), uma vez que preserva grande área de cartilagem e pode ser aplicada em cães de todas as idades (ROUSH, 1993; SLOCUM \& SLOCUM, 1993). Além disso, permite o retorno mais rápido da função do membro quando comparada à sulcoplastia troclear (SEGUIN \& HARARI, 1994). O primeiro relato da realização dessa técnica foi publicado por Slocum em 1982 (SLOCUM \& SLOCUM, 1993).

\footnotetext{
${ }^{1}$ Aluno do Curso de Medicina Veterinária, Faculdade de Medicina Veterinária e Zootecnia (FMVZ) Unesp Botucatu, Bolsista de Iniciação Científica CNPq.

${ }^{2}$ Médico Veterinário, Professor Adjunto, FMVZ, Unesp Botucatu, Departamento de Cirurgia e Anestesiologia Veterinária. 18618000, Botucatu, São Paulo. E-mail:sheilacr@fmvz.unesp.br Autor para correspondência.

${ }^{3}$ Médico Veterinário, Professor Assistente Doutor, Departamento de Clínica Veterinária, FMVZ, Unesp Botucatu.

${ }^{4}$ Médico Veterinário, Mestrando, FMVZ - Unesp Botucatu.

${ }^{5}$ Biólogo, Professor Assistente Doutor, Instituto de Biociências, Unesp Botucatu.
} 
O procedimento de sulcoplastia de recessão pode ser efetuado com serras oscilatórias, lâminas de várias amplitudes para variáveis profundidades (SLOCUM \& SLOCUM, 1993), ou serra X-Acto nํㅜ 234 ou nํㅜ 236 (SEGUIN \& HARARI, 1994). Consiste em retirar uma cunha óssea, com posterior recolocação na chanfradura (VASSEUR, 1993). De acordo com alguns autores (ROUSH, 1993; SLOCUM \& SLOCUM, 1993; VASSEUR, 1993; SEGUIN \& HARARI, 1994), não haveria necessidade de fixação, uma vez que a pressão exercida pela patela seria suficiente para manter a cunha em seu leito. SLOCUM \& SLOCUM (1998) afirmaram que, em suas experiências clínicas, nenhuma cunha troclear migrou, quando assentada adequadamente.

Embora a cunha seja enxerto osteocondral livre, o osso adjacente do côndilo femoral proporciona suprimento sangüíneo para a porção óssea, ao passo que a cartilagem articular recebe nutrientes do fluído articular (SLOCUM \& SLOCUM, 1998). Segundo SEGUIN \& HARARI (1994), a cicatrização subcondral ocorre em oito semanas e os bordos laterais da cunha formam fibrocartilagem. Uma vez que a patela continua mantendo contato com a cartilagem hialina da tróclea do fêmur, as probabilidades de aparecimento de alterações degenerativas na articulação são menores comparativamente aos outros métodos (ROUSH, 1993; SLOCUM \& SLOCUM, 1993).

Em algumas situações, faz-se necessário o aprofundamento do sulco de forma assimétrica, com o intuito de compensar a deformidade troclear (SLOCUM \& SLOCUM, 1993). No entanto, isto pode dificultar o encaixe da cunha óssea de forma precisa. Nesses casos seria benéfica a utilização de um produto que auxiliasse na estabilização, sem interferir na cicatrização.

Atualmente, a cola Vetbond®, composta por n-butil cianoacrilato, está sendo bastante divulgada na medicina veterinária brasileira, como auxiliar para a aproximação de tecidos em cortes superficiais, esfoliações, remoção de unhas, extrações de dentes, entre outros (3M do Brasil).

A aplicação de cianoacrilatos tem sido muito contraditória, especialmente em ortopedia. Conforme ARUN (2002), cianoacrilatos de cadeia mais curta (metil e etil-cianoacrilato) são histotóxicos e os de cadeia mais longa (butil e isobutil-cianoacrilato) menos; entre eles o butil-2-cianoacrilato foi o mais comumente usado para fixação óssea. Cianoacrilatos de comprimento de cadeia biologicamente tolerável não desenvolvem união com osso esponjoso, apenas com osso cortical após meticulosa preparação da superfície para facilitar a aderência (WEBER \& CHAPMAN, 1984).
LIGHTERMAN \& FARRELL (1962), ao utilizarem cola de metilcianoacrilato em fraturas mandibulares de cães, verificaram refraturas em diversos animais em um intervalo de 10 dias, provavelmente associadas à remoção enzimática do produto.

O monômero viscoso do isoamil-2cianoacrilato foi utilizado por HARPER (1988), para avaliar a habilidade do produto em manter a redução de um fragmento osteocondral instável, no joelho de coelhos, durante o processo de cicatrização. $\mathrm{O}$ adesivo não causou toxicidade ao osso viável adjacente e à cartilagem, além de ter proporcionado significante estabilidade do fragmento osteocondral.

EKELUND \& NILSSON (1991), após estudo em ratos, com matriz óssea alogênica desmineralizada e n-butil-2-cianoacrilato, concluíram que adesivos teciduais devem ser usados com cuidado em fraturas, por causarem efeitos adversos como inibição da regeneração óssea, reação de corpo estranho e impedimento da consolidação.

AMARANTE et al. (1995), ao compararem a cola de n-butil cianoacrilato com placas e parafusos na fixação de fragmentos ósseos do esqueleto crânio facial de suínos, concluíram que ambos os métodos foram efetivos, apesar de ocorrer reação de corpo estranho na área circundada pela cola. Todas as áreas mostraram osso viável com osteoblastos normais e nenhuma evidência de necrose ou reabsorção óssea.

Alfa-cianoacrilato foi aplicado para fixação de fragmento ósseo de tíbia de galinhas, ocorrendo boa estabilidade do fragmento, boa consolidação óssea e ausência de reação de corpo estranho (CAROLI et al., 1997).

ARON \& GORSE (1991) estabilizaram, em seis cães, fragmentos osteocondrais e condrais com n-butil-2-cianocrilato. Exames radiográficos não foram adequados para visibilizar a cicatrização dos fragmentos. Entretanto, nenhuma mudança degenerativa significante foi observada em qualquer articulação.

Em virtude do exposto, o trabalho teve por objetivos analisar a cola composta por n-butil cianoacrilato, como um auxiliar na fixação da cunha óssea no procedimento da sulcoplastia de recessão e sua interferência no processo cicatricial.

\section{MATERIAL E MÉTODOS}

Foram utilizados nove coelhos da raça Norfolk, machos, jovens, com peso médio inicial entre 3,0 e $3,5 \mathrm{~kg}$, fornecidos pelo Biotério Central da Universidade Estadual Paulista - Campus de Botucatu. 
Os animais foram alocados em gaiolas individuais $60 \times 60 \times 60 \mathrm{~cm}$, suspensas do solo, com água e ração comercial ad libitum.

Após jejum de seis horas, foram tranqüilizados com acepromazina na dose de $0,1 \mathrm{mg}$ $\mathrm{kg}^{-1} / \mathrm{IV}$. Realizou-se tricotomia dos membros pélvicos e área lombosacra e, em seguida, efetuada anestesia epidural com uma associação de lidocaína $2 \%$ e bupivacaína $0,5 \%$, na proporção de $1: 1$, e na dose de $0,25 \mathrm{ml}$ para cada $1,0 \mathrm{~kg}$ de peso.

Os coelhos foram posicionados em decúbito dorsal e a anti-sepsia da área cirúrgica efetuada com álcool iodado. Realizou-se incisão parapatelar medial na pele e, logo após, na cápsula articular. Com a patela afastada lateralmente por manipulação digital e o joelho flexionado, demarcaramse linhas lateral e medial à cartilagem da tróclea femoral, e seccionou-se uma cunha em formato de "V", composta de cartilagem e osso subcondral, com uma serra para ourives antílope $\mathrm{n}^{\mathrm{o}} 2 / 0$ adaptada a um arco de serra Grobet $80 \mathrm{~mm}$. A profundidade do "V" foi limitada até o nível da união dos ligamentos cruzados. No joelho direito, antes da colocação da cunha em seu leito, aplicaram-se duas gotas da cola n-butil cianoacrilato $^{\text {a }}$, ao passo que no joelho esquerdo, considerado como controle, a cunha ósseocartilaginosa foi recolocada em seu leito sem aplicação de medicamento. Foram utilizadas suturas contínua simples na cápsula articular e retináculo, e tipo cushing no tecido subcutâneo, ambas com náilon monofilamento no 4-0. A síntese da pele foi realizada em pontos simples separados utilizando o mesmo fio.

A antibioticoterapia foi iniciada três horas antes do procedimento cirúrgico, com ampicilina benzatina ${ }^{\mathrm{b}}$ na dose de $25 \mathrm{mg} / \mathrm{kg}$ por via subcutânea e, mantida a cada 24 horas, durante cinco dias. Ao final da cirurgia foi administrada buprenorfina ${ }^{c}$ na dose de $0,05 \mathrm{mg} / \mathrm{kg}$, que foi reaplicada a cada 12 horas, durante cinco dias. Realizou-se limpeza da ferida cirúrgica, uma vez ao dia, com uma solução de iodopolivinilpirrolidona e solução fisiológica (1:10) até a cicatrização. Os pontos cutâneos foram removidos aos sete dias de pós-operatório. Os animais foram avaliados quanto ao apoio do membro operado, presença ou não de edema e sinais de infecção.

Para a realização da técnica de exame anatomopatológico, foram submetidos à eutanásia, com pentobarbital sódico ${ }^{\mathrm{d}}$ e cloreto de potássio ${ }^{\mathrm{e}}$, três animais aos cinco, 15 e 30 dias de pós-operatório. A avaliação macroscópica incluiu a região da cunha, cartilagem articular dos côndilos femorais e face articular proximal da tíbia, tecidos capsular e ligamentares, meniscos, patela e líquido sinovial. Para o exame histológico, os tecidos moles e patelas de ambos os joelhos foram removidos e os ossos longos (fêmur e tíbia) separados. O fêmur foi seccionado 3,0 $\mathrm{cm}$ acima da linha articular e a porção contendo a cunha ósseo-cartilaginosa foi fixada em formalina tamponada $10 \%$. Posteriormente foi descalcificada com solução de EDTA e foram obtidos fragmentos centrados na área da cunha. Estes foram incluídos em metacrilato glicol, cortados em micrótomo comum (secções de 3 $\mu \mathrm{m})$ e corados com Tricrômio de Masson e Hematoxiliaeosina.

\section{RESULTADOS}

Os animais apoiaram os membros pélvicos a partir do pós-operatório imediato, não havendo sinais de claudicação. A exceção foi um coelho que apresentou déficit neurológico pós-anestésico com discreta atrofia do membro pélvico esquerdo. Nos primeiros três dias após o procedimento cirúrgico verificou-se edema moderado na articulação do joelho em todos os coelhos. Não foram detectados sinais de infecção e as feridas cicatrizaram adequadamente.

$\mathrm{Na}$ avaliação macroscópica notou-se, em todos os animais, a estabilização da cunha ósseocartilaginosa em seu leito receptor nos diferentes momentos de observação (Figura 1). Em ambos os joelhos houve tendência de perda de brilho e irregularidades finas da superfície articular no sulco da tróclea, côndilo medial, côndilo lateral e patela. $\mathrm{O}$ joelho direito apresentou essas lesões mais evidentes que o esquerdo aos cinco dias de pós-operatório. A área de junção da cunha ósteo-cartilaginosa tornouse menos visível aos 15 e 30 dias, em especial no joelho controle. Não foram detectadas alterações na cápsula articular, ligamentos e meniscos. O líquido sinovial apresentou coloração palha (amarelo claro) em todos os coelhos.

$\mathrm{Na}$ avaliação histológica das trócleas esquerda e direita, aos cinco dias de pós-cirúrgico, verificou-se nas bordas do leito receptor e cunha óssea a presença de tecido ósseo necrótico e discreto infiltrado inflamatório constituído por mono e polimorfonucleares. A cartilagem articular mostrou-se descontínua, sendo o limite entre a cartilagem da cunha óssea e cartilagem do leito receptor preenchido por fibrina. Aos 15 dias de pós-operatório, a tróclea esquerda apresentava nas bordas do leito receptor presença discreta de restos necróticos e grande número de osteoclastos, além de vascularização mais abundante. No limite entre a cartilagem da cunha óssea, observou-se tecido de granulação que proliferava a partir do leito receptor, acompanhado de reação 


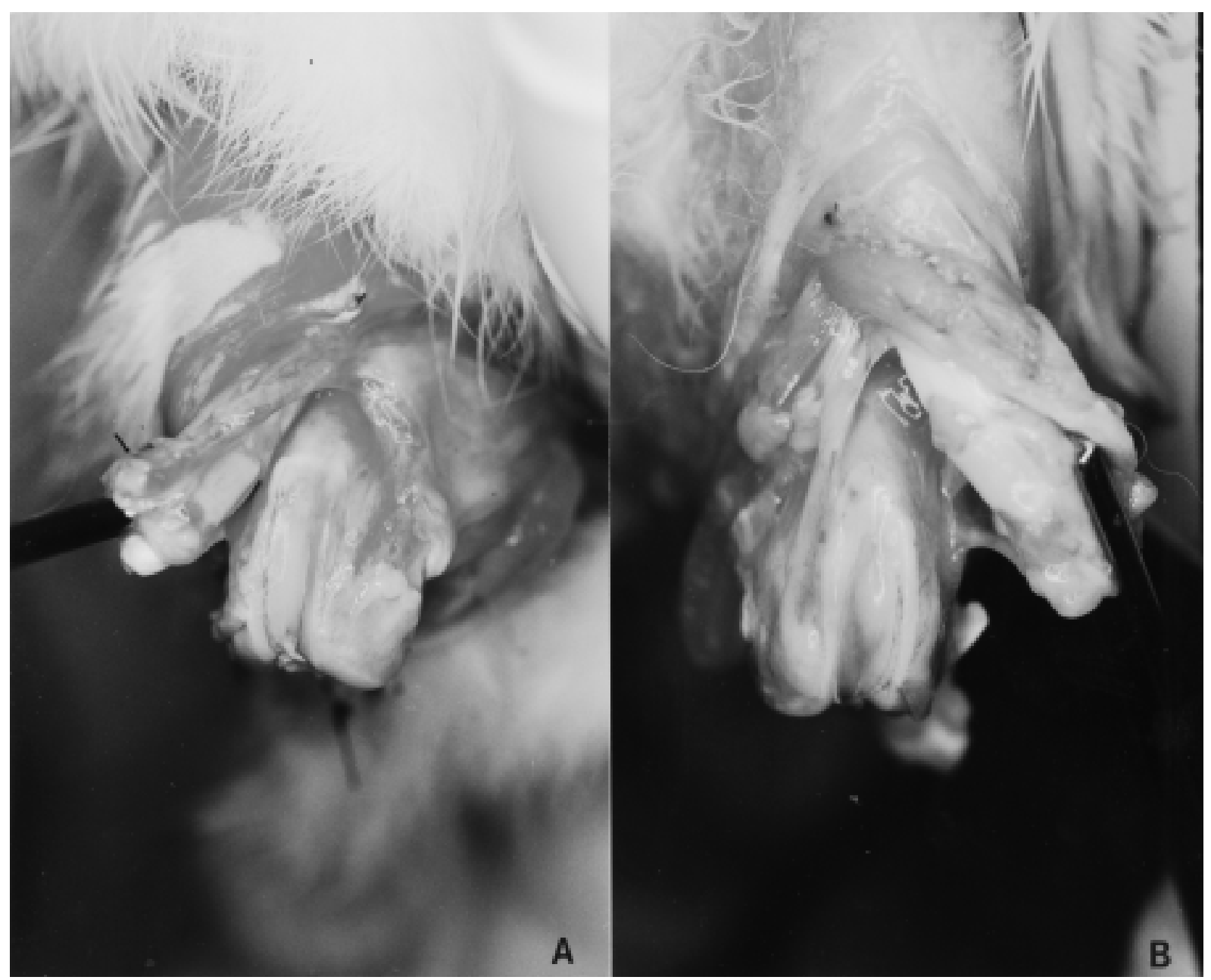

Figura 1 - Aspecto macroscópico do sulco da tróclea dos joelhos direito (a) e esquerdo (b) aos 15 dias de pós-operatório. Em ambos joelhos observa-se bom posicionamento da cunha óssea. No entanto, na tróclea esquerda (controle) é visível o início do restabelecmento da cartilagem no limite da cunha

leucocitária constituída por mononucleares. Na tróclea direita havia restos necróticos nas bordas do leito receptor e notou-se, no limite entre a cartilagem da cunha óssea, presença discreta de tecido de granulação, que proliferava a partir do leito receptor, acompanhada de reação leucocitária constituída por mononucleares. Aos 30 dias de pós-operatório, verificou-se, na tróclea esquerda, restabelecimento da continuidade da cartilagem articular e das trabéculas óssea subcondrais (Figura 2). Não havia sinais de reação inflamatória em quaisquer das áreas examinadas. Na tróclea direita, ainda não existia a união completa entre o leito receptor e a cunha óssea (Figura 3). Nas bordas do leito receptor, observou-se presença discreta de restos necróticos e grande número de osteoclastos. A vascularização da região tornou-se mais abundante. No limite entre a cartilagem da cunha óssea, havia presença de tecido de granulação que proliferava a partir do leito receptor, acompanhada de reação leucocitária constituída por mononucleares.

\section{DISCUSSÃO}

Embora tenha havido tendência de perda de brilho e irregularidades finas da superfície articular no sulco da tróclea, côndilo medial, côndilo lateral e patela, a ausência de alterações na cápsula articular, ligamentos, meniscos e líquido sinovial são fatores favoráveis; como referido por ROUSH (1993) e SLOCUM \& SLOCUM (1993), esse método de aprofundamento do sulco é um dos procedimentos com menor probabilidade de aparecimento de alterações degenerativas articulares. 


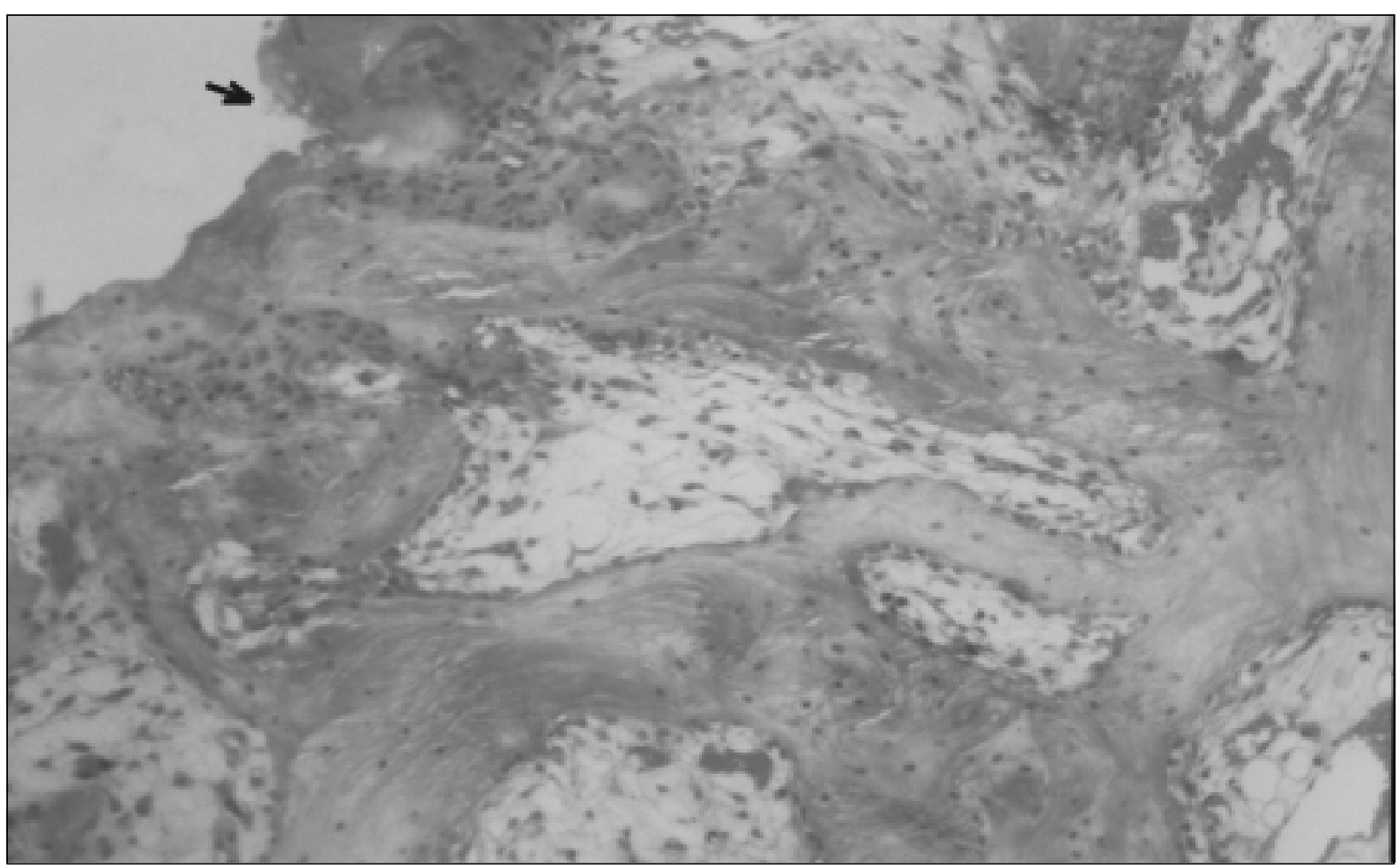

Figura 2 - Aspecto microscópico da superfície articular da tróclea esquerda (controle) aos 30 dias de pós-operatório. Verifica-se o restabelecimento da continuidade da cartilagem articular e das trabéculas ósseas subcondrais (seta). (HE, 100X)

A boa estabilização da cunha óssea cartilaginosa no grupo controle, em todos os períodos de observação, indicou que a pressão exercida pela patela, como citado por outros autores (ROUSH, 1993; SLOCUM\& SLOCUM, 1993; VASSEUR, 1993; SEGUIN \& HARARI, 1994), foi suficiente para mantê-la em seu leito. Desta forma, neste modelo experimental não foi possível avaliar o poder de adesão da cola, sendo o mesmo um tanto controverso na dependência da composição do produto e tipo de lesão induzida (LIGHTERMAN \& FARRELL, 1962; WEBER \& CHAPMAN, 1984; HARPER, 1988; ARON \& GORSE, 1991; CAROLI et al., 1997; ARUN, 2002).

Apesar de SEGUIN \& HARARI (1994) citarem que a cicatrização subcondral em cães geralmente ocorre em oito semanas e com formação de fibrocartilagem nos lados da cunha, no joelho controle essa foi observada no $30^{\circ}$ dia e com presença de cartilagem.

Pela análise histológica, a vascularização foi mais abundante no tróclea esquerda que direita, especialmente aos 15 dias de pós-operatório, indicando que a cola interferiu no suprimento sangüíneo, provavelmente como uma barreira física. Aos 30 dias de pós-cirúrgico, verificou-se na tróclea esquerda restabelecimento da continuidade da cartilagem articular e das trabéculas ósseas subcondrais, ao passo que, na tróclea direita, não existia união completa, representando um retardo do processo cicatricial. A interferência da cola n-butil cianoacrilato na indução e formação óssea foi também verificada por EKELUND \& NILSSON (1991), em estudo com matriz óssea alogênica desmineralizada em ratos. Por sua vez, AMARENTE et al. (1995) não detectaram alterações no processo cicatricial quando fixaram fragmentos ósseos do esqueleto crânio facial em suínos.

Não foram observadas histologicamente reações de corpo estranho nos joelhos em que se aplicou a cola de n-butil cianoacrilato, diferindo dos achados de EKELUND \& NILSSON (1991) e AMARANTE et al. (1995). Contudo, CAROLI et al. (1997) não verificaram reação por corpo estranho, ao utilizarem alpha-cianoacrilato para fixação de fragmento ósseo de tíbia de galinha.

\section{CONCLUSÕES}

Foi possível concluir que o uso da cola n-butil cianoacrilato na sulcoplastia 


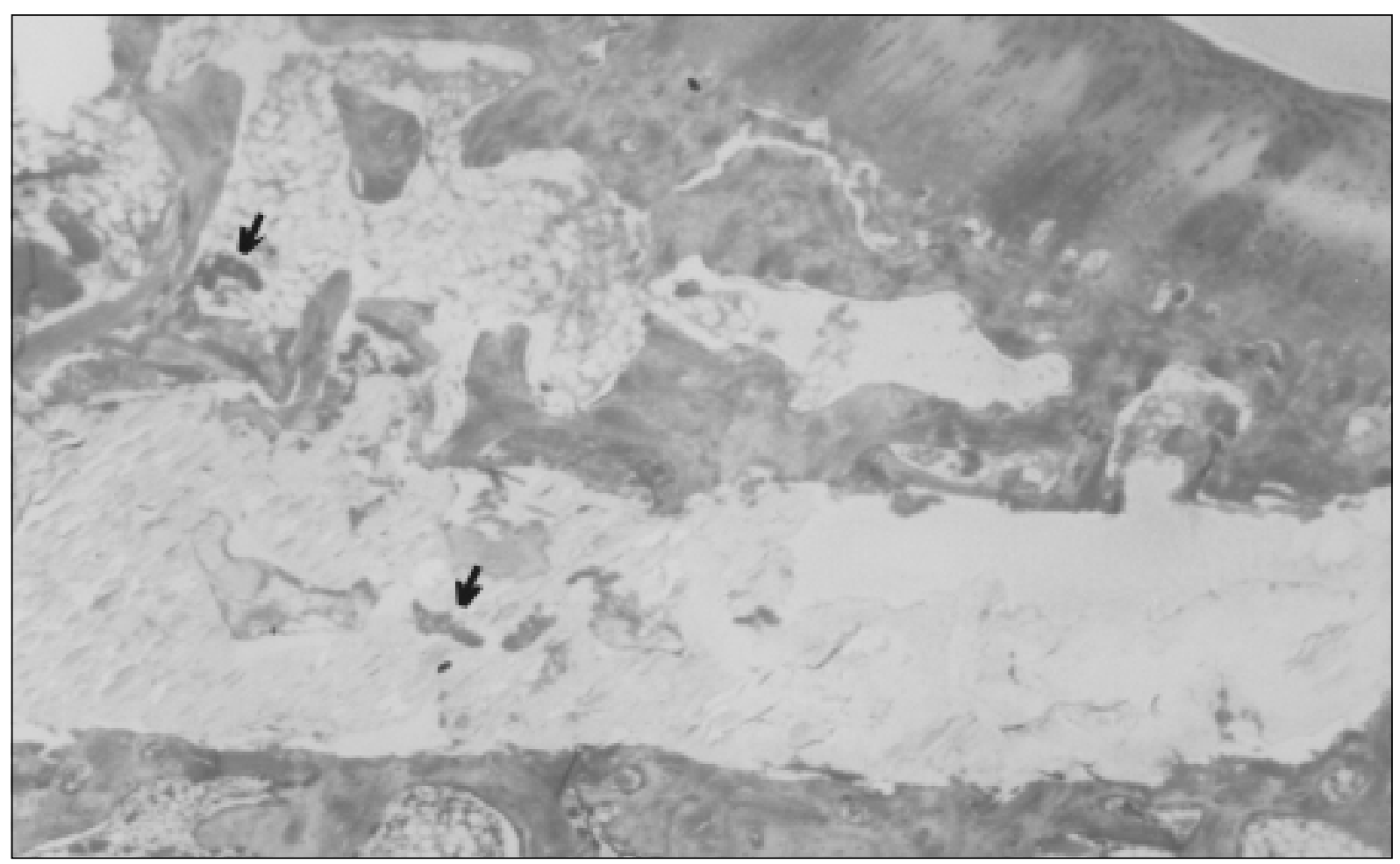

Figura 3 - Aspecto microscópico da superfície articular da tróclea direita aos 30 dias de pós-operatório. Nota-se que ainda não existe união completa entre cunha óssea e leito receptor. Nas bordas do leito receptor há presença discreta de restos necróticos (seta). (HE, $32 \mathrm{X})$

de recessão, em coelhos, retardou o processo cicatricial.

\section{FONTES DE AQUISIÇÃO}

a - Vetbond - 3M do Brasil Ltda - Via Anhanguera, Km 110 Campinas, SP

b - Optacilin - Byk Química e Farmacêutica Ltda - Av. Casa Grande, 850 - Diadema, SP

c - Tengesic - Schering-Plough - Estrada dos Bandeirantes, 3091 - Rio de Janeiro, RJ

d - Hypnol - Cristália - Rodovia Itapira-Lindóia, Km 14 Itapira, SP

e - Cloreto de potássio - Darrow Lab. S/A - Rua Marques de Olinda, 69 - Botafogo, RJ

\section{REFERÊNCIAS BIBLIOGRÁFICAS}

ARON, D.N.; GORSE, M.J. Clinical use of n-butyl 2 cyanoacrylate for stabilization of osteochondral fragments: preliminary report. Journal American Animal Hospital Association, v.27, n.2, p.203-201, 1991.

ARUN, K.G. The current status of tissue glues: I. For bone fixation. Plastic Reconstructive Surgery, v.109, n.7, p.2581-2583, 2002.

AMARANTE, M.T.J. et al. Cyanoacrylate fixation of the craniofacial skeleton: an experimental study. Plastic and
Reconstructive Surgery, v. 95, n. 4, p.639- 645, 1995.

CAROLI, A. et al. An experimental study of a cyanoacrylate biological adhesive in view of its use in the fixation of various fractures of the fingers. Annales de Chirurgie de la Main et du Membre Superieur, v.16, n.2, p.138-145, 1997.

EKELUND, A.; NILSSON, O.S. Tissue adhesives inhibit experimental new bone formation. International Orthopaedics, v.15, n.4, p.331-334, 1991.

HARPER, M.C. Stabilization of osteochondral fragments using limited placement of cyanoacrylate in rabbits. Clinical Orthopaedics and Related Research, v.231, p.272-276, 1988.

LIGHTERMAN, I.; FARREL, J.J. Treatment of experimentally induced mandibular fractures with plastic polymers. Plastic Surgery, v.13, p.466-468, 1962.

ROUSH, J.K. Canine patellar luxation. Veterinary Clinics of North America: Small Animal Practice, v.23, n.4, p.855-867, 1993.

SEGUIN, B.; HARARI, J. Trochlear wedge recession for the treatment of patellar luxation. Canine Practice, v.19, n.6, p.24-26, 1994.

SLOCUM, B.; SLOCUM, T.D. Trochlear wedge recession for medial patellar luxation. Veterinary Clinics of North America: Small Animal Practice. v.23, n.4, p.869-875, 1993. 
SLOCUM, B.; SLOCUM, T.D. Trochlear wedge recession for medial patellar luxation. In: BOJRAB, M.J.; ELLISON, G.W.; SLOCUM, B. Current techniques in small animal surgery. 3.ed. Baltimore : Williams \& Wilkins, 1998. p. $1232-1234$

VASSEUR, P.B. Stifle joint. In: SLATTER, D. Textbook of small animal surgery. 2.ed. Philadelphia : Saunders, 1993. V.2, chap.137, p.1817-1865.

WEBER, S.C.; CHAPMAN, M.W. Adhesives in orthopaedic surgery. A review of the literature and in vitro bonding strengths of bone-bonding agents. Clinical Orthopaedics and Related Research, v.191, p.249-261, 1984. 